\title{
Cor Pulmonale as a Result of Chronic Nasopharyngeal Obstruction Due to Hypertrophied Tonsils and Adenoids
}

\author{
F. J. MACARTNEY, J. PANDAY, and OLIVE SCOTT \\ From the Department of Paediatric Cardiology, Leeds Regional Thoracic Surgical Centre
}

It is important to recognize that heart failure in young children can be due to causes other than congenital heart disease. A syndrome has recently been recognized in children which can lead to gross cardiac failure and yet can apparently be permanently cured simply by removing the tonsils and adenoids. It is the syndrome of cor pulmonale due to hypoventilation resulting from chronic nasopharyngeal obstruction. Since the first reports (Menashe, Farrehi, and Miller, 1965; Noonan, 1965) others have appeared, bringing the total of reported cases to 16 (Luke et al., 1966; Levy et al., 1967; Ainger, 1968). We present here the clinical, electrocardiographic, and radiological findings in 3 patients, together with the results of cardiac catheterization in 2 of them.

\section{Case Reports}

Case 1. This child, aged $2 \frac{3}{4}$ years, was first admitted to another hospital when 15 months old, with a history of marked stridor, particularly at night, a persistent purulent nasal discharge, and a chest infection. He improved after treatment with antibiotics and was discharged after a fortnight. 2 months later he was readmitted with a history of cough and breathlessness for $\mathbf{4}$ days and purulent nasal discharge. Stridor had been noticed which was worse at night, and cyanosis had also been observed when he was asleep. In addition, his parents had noticed that he was drowsy in the morning and that he took a long time to become completely awake. His chest infection was cured by antibiotics, but the cyanosis at night, and morning drowsiness persisted. He had no heart murmurs or heart failure, but $x$-ray of his chest showed cardiac enlargement. An electrocardiogram (ECG) showed evidence of right atrial and right ventricular hypertrophy.

He was referred for a cardiological opinion because of the unexplained cardiomegaly. When first seen he had signs of a moderate degree of pulmonary hyper-

Received March 28, 1969. tension and his heart size was increased radiologically. His ECG showed marked right atrial and right ventricular hypertrophy. Primary pulmonary hypertension was considered the most likely diagnosis, but some form of cardiomyopathy was also considered. Since he had improved and his heart size had decreased considerably by the time we saw him, he was not regarded as an urgent problem and his name was listed for cardiac catheterization. Within 3 weeks, however, his condition again deteriorated and he was admitted to the Cardiac Unit as an emergency.

On examination he was in gross right heart failure, with pitting oedema of the lower limbs to the level of the groins, marked facial oedema, moderate hepatomegaly, and shifting abdominal dullness. $\mathrm{He}$ was mildly cyanosed but there was no finger clubbing. His facies were adenoidal, and he snuffled and breathed through his mouth all the time. At night, or whenever he was lying on his back, he developed marked inspiratory stridor, increasing cyanosis, and sometimes complete respiratory obstruction. It was difficult to rouse him from sleep and he did not reach full consciousness for 10 minutes. He frequently fell asleep during the day. His tonsils were greatly enlarged, meeting in the mid-line. He had moderate sinus tachycardia, a $5 \mathrm{~cm}$. A wave in the venous pulse, and a slight right ventricular lift. There were no murmurs, but there was a loud pulmonary click and the second sound was single and much accentuated. No added sounds were audible in the chest.

ECG (Fig. 1) showed marked right ventricular hypertrophy and strain, and severe right atrial hypertrophy. The chest $x$-ray (Fig. 2) showed a greatly enlarged heart, with a particularly dilated main pulmonary artery, and diffuse fluffy opacities in both lung fields. Three blood cultures were sterile, and blood $\mathrm{Hb}$ was $13 \cdot 7 \mathrm{~g}$. $/ 100 \mathrm{ml}$., white cell count 13,200/cu.mm., and erythrocyte sedimentation rate $1 \mathrm{~mm}$. $/ \mathrm{hr}$.

He was treated with digoxin and large doses of frusemide with potassium supplements, but despite this he deteriorated, continuing to gain weight, and becoming more somnolent and cyanosed. He was put in an oxygen tent one evening; the following morning he was no less cyanosed and it took 20 minutes of vigorous 
shaking to rouse him from sleep. The remarkable resemblance between this behaviour and that of a chronic bronchitic whose respiratory centre has become insensitive to a rise in arterial Pco., led to the correct diagnosis. $\mathrm{O}_{2}$ therapy was discontinued, and an arterial blood sample taken while the child was still asleep showed a $\mathrm{PCO}_{2}$ of $69 \mathrm{~mm}$. $\mathrm{Hg}$, a $\mathrm{Po}_{2}$ of $65 \mathrm{~mm} . \mathrm{Hg}$, and a $p \mathrm{H}$ of $7 \cdot 35$. That such a sample could be taken at all is a measure of the depression of his central nervous system during sleep.

Further medical treatment and training in sleeping in the prone position, which relieved respiratory obstruction almost completely, improved his condition sufficiently for cardiac catheterization to be performed. Right heart catheterization was performed from the right saphenous vein without sedation; the femoral artery was also catheterized by an open Seldinger technique.

The results (Tables I and II) showed pulmonary hypertension, the pulmonary artery mean pressure never dropping below $24 \mathrm{~mm}$. $\mathrm{Hg}$. The highest mean value $(44 \mathrm{~mm} . \mathrm{Hg}$ ) was the first record when the child was asleep and breathing air, at a time when there was considerable desaturation of the aortic blood $\left(\mathrm{O}_{2}\right.$ sat. $\left.=70 \cdot 5 \%\right)$ and a high $\mathrm{PcO}_{2}$ of $76 \mathrm{~mm}$. $\mathrm{Hg}$. Crying was accompanied by a reduction in the pulmonary artery pressure to $26 \mathrm{~mm}$. $\mathrm{Hg}$, and at the same time, as expected, by a rise in arterial oxygen saturation and a fall in $\mathrm{PCO}_{2}$. The arterial $\mathrm{PCO}_{2}$ was abnormally high throughout the test and the arterial $\mathrm{O}_{2}$ saturation abnormally low except when $O_{\text {. }}$ was breathed. It was not possible to test the effect of breathing $\mathrm{O}_{2}$ while the child was asleep, but $100 \% \mathrm{O}_{2}$ given while he was crying had little effect. Intubation with an endotracheal tube was carried out but was technically difficult because of his short neck, large tonsils and tongue, and lax epiglottis. He required atropine $0.2 \mathrm{mg}$., and suxamethonium $10 \mathrm{mg}$. i.v., followed by fluothane and nitrous oxide before intubation was possible. The patient was then allowed to recover consciousness. The figures at $100 \mathrm{~min}$. (Table II) were taken just before he woke up, with the endotracheal tube in situ. Shortly afterwards it was coughed out.

Since these results were considered to prove the diagnosis of cor pulmonale secondary to hypoventilation due to upper respiratory obstruction, his tonsils and adenoids were removed on May 30, 1968. At operation the epiglottis was short, and was curled and collapsed on to the posterior wall of the pharynx. When the epiglottis was lifted up he had an excellent airway. The tonsils were large, but no bigger than those often seen in children without stridor or obstruction of the upper airways. The tonsils and adenoids were removed without difficulty. Within 24 hours the child was much improved and was breathing well without any stridor. The surgeon thought that the respiratory obstruction had been caused by the combination of the large broad epiglottis and the large tonsils.

The child continued to make excellent progress. When reviewed at Out-patients 1 month after his operation he was still mouth breathing at times but was otherwise well. Examination of his heart was normal, there being no evidence of pulmonary hypertension. His ECG 1 month after operation showed normal $\mathbf{P}$ waves in lead II and the $R$ wave in V3R had fallen from $21 \mathrm{~mm}$. to $7 \mathrm{~mm}$. (Fig. 3). A further record on October 22, 5 months after operation, was normal, and by this time the child no longer breathed through his mouth. Radiography showed a heart of almost normal size (Fig. 4).

Cardiac catheterization was repeated without any sedation on October 24 . The results (Table II) showed a pulmonary artery pressure of $30 / 5 \mathrm{~mm}$. $\mathrm{Hg}$ (mean pressure $12 \mathrm{~mm}$. $\mathrm{Hg}$ ); $\mathrm{O}_{2}$ saturations showed no evidence of any left-to-right shunt.

Case 2. This child, aged 20 months, had been admitted to hospital on numerous occasions during his life with the diagnosis of asthmatic bronchitis and nasal obstruction. On July 27, 1967, skull $x$-ray after insertion of Hypaque into both nostrils showed posterior nasal obstruction due to adenoidal pads and excluded choanal atresia. He was readmitted to hospital on April 26, 1968, with the same complaints of dyspnoea, nasal discharge, and noisy breathing, and in the course of his stay in hospital developed severe right heart failure which required vigorous treatment with digitalis, diuretics, and antibiotics. At no time did he appear somnolent.

At the time of admission on May 20, he had marked inspiratory stridor particularly in the supine position, slight cyanosis, and early finger clubbing. There was slight hepatomegaly but no oedema. There was a slight right parasternal heave. Auscultation revealed no abnormality except for an accentuated pulmonary second sound. His tonsils were moderately enlarged. There was no nasal discharge.

ECG showed right atrial hypertrophy and deep symmetrical $T$ wave inversion over the right ventricular leads, as far as V4, though on QRS voltage criteria there was no right ventricular hypertrophy. The frontal QRS axis was $-170^{\circ}$. The chest $x$-ray showed moderate cardiac enlargement and some congestion of the lung fields.

Two days later, cardiac catheterization (results in Table III) was carried out without sedation. The child's condition was better than that of Case 1 at the time of catheterization. The same abnormalities were present but were not nearly so striking. The arterial $\mathrm{PCO}_{2}$ was abnormally raised except during crying, and the arterial $p H$ correspondingly low. The administration of $\mathrm{O}_{2}$ in the resting state was accompanied by a rise of arterial $\mathrm{PCO}_{2}$. The arterial $\mathrm{O}_{2}$ saturation was abnormally low, and increased during crying. There was slight but definite pulmonary hypertension, which was increased during the administration of $\mathrm{O}_{2}$. The pulmonary artery pressure was increased during crying despite the fall in arterial $\mathbf{P C O}_{2}$ and the rise in arterial $\mathrm{O}_{2}$ saturation. This child was not intubated.

The upper respiratory tract was investigated on July 17, and enlarged tonsils and adenoids were found, but the epiglottis was normal. His tonsils and adenoids were removed and he improved. Digoxin was dis- 


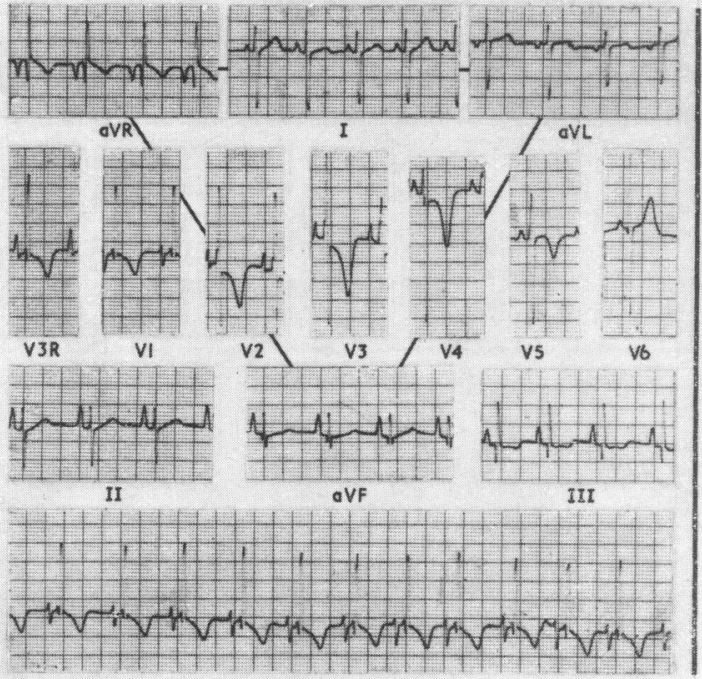

FIG. 1. ECG before tonsillectomy in Case 1, shows right atrial enlargement (tall peaked $P$ waves in lead II); right ventricular enlargement (tall $R$ waves in $V 3 R$ and and V1); $T$ wave inversion from V3R to V5.

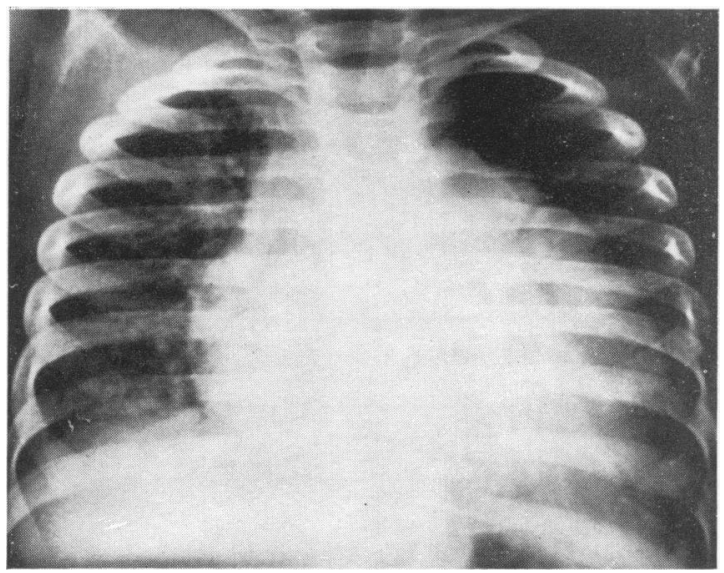

FIG. 2.-Chest $\mathrm{x}$-ray before tonsillectomy in Case 1 shows marked cardiomegaly.

continued on July 28 . When seen 1 month later, there was no evidence of heart failure and he was breathing well through his nose with his mouth closed. He continued to make satisfactory progress and there was no recurrence of heart failure. He died after an accident on September 10, in which his liver was ruptured. Necropsy was performed and there was no abnormality of the heart either macroscopically or microscopically.

Case 3. This boy aged 3 years showed the same syndrome but in a less severe form. He was admitted

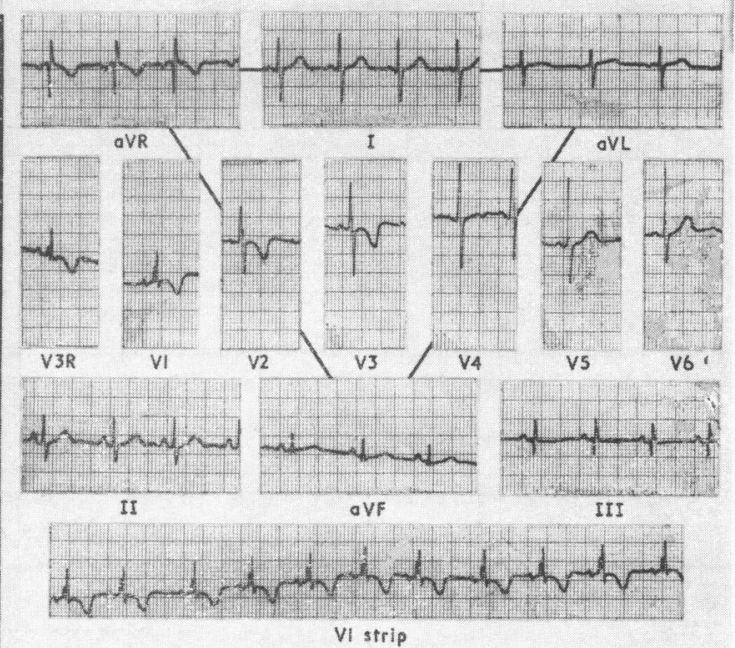

Fig. 3.-ECG 1 month after tonsillectomy in Case 1, shows normal $P$ waves in lead II and normal right ventricular activity.

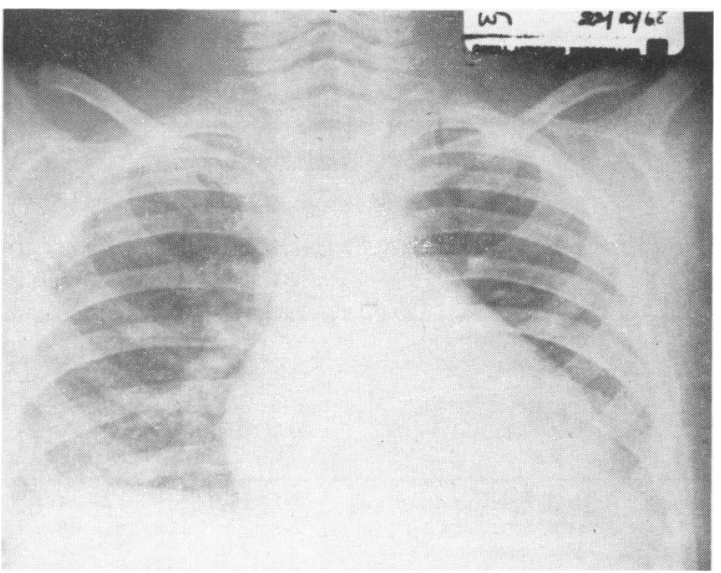

FIG. 4.-Chest $\mathrm{x}$-ray in Case 1, 5 months after tonsillectomy, shows marked reduction in heart size compared with Fig. 2.

to hospital for tonsillectomy and adenoidectomy because of frequent sore throats. He had large tonsils and cervical glands. The nursing staff reported that he had cyanotic attacks during the night. No heart murmurs were heard, but $x$-ray of his chest showed an enlarged heart (Fig. 5) and he was referred for a cardiological opinion. On April 7, 1967, he was mouth breathing and had minimal cyanosis at rest. There was profuse purulent nasal discharge. There were no significant heart murmurs, but his chest $x$-ray showed cardiac enlargement with a large right atrium and 
TABLE I

Results of Cardiac Catheterization in Two Patients with Cor Pulmonale due to Upper Respiratory Obstruction

\begin{tabular}{|c|c|c|c|c|c|c|c|c|c|c|}
\hline \multirow{2}{*}{ Case No. } & \multirow{2}{*}{$\frac{\text { IVC }}{\begin{array}{c}\mathrm{O}_{2} \text { Sat. } \\
(\%)\end{array}}$} & \multirow{2}{*}{$\frac{\text { SVC }}{\substack{\mathrm{O}_{2} \text { Sat. } \\
(\%)}}$} & \multicolumn{2}{|c|}{ Right Atrium } & \multicolumn{2}{|c|}{ Right Vent. } & \multicolumn{2}{|c|}{ Pulm. Art. } & \multicolumn{2}{|c|}{ Aorta } \\
\hline & & & $\begin{array}{c}\text { Press. } \\
(\mathrm{mm} . \mathrm{Hg})\end{array}$ & $\begin{array}{c}\mathrm{O}_{2} \text { Sat. } \\
(\%)\end{array}$ & $\begin{array}{c}\text { Press. } \\
(\mathrm{mm} . \mathbf{H g})\end{array}$ & $\begin{array}{c}\mathrm{O}_{2} \text { Sat. } \\
(\%)\end{array}$ & $\begin{array}{c}\text { Press. } \\
(\mathrm{mm} . \mathbf{H g})\end{array}$ & $\underset{(\%)}{\mathrm{O}_{2} \text { Sat. }}$ & $\begin{array}{c}\text { Press. } \\
(\mathrm{mm} . \mathrm{Hg})\end{array}$ & $\begin{array}{c}\mathrm{O}_{2} \text { Sat. } \\
(\%)\end{array}$ \\
\hline 1 & 67 & 63.5 & -3 & $\begin{array}{c}65,64, \\
66 \cdot 5\end{array}$ & $76 /-3$ & 62 & $76 / 28$ & 62 & $134 / 64$ & $70 \cdot 5$ \\
\hline 2 & $63 \cdot 5$ & 65 & -2 & $\begin{array}{c}64,65 \\
66 \cdot 5\end{array}$ & $33 / 0$ & $64 \cdot 5$ & $33 / 4$ & 62 & $121 / 68$ & 86 \\
\hline
\end{tabular}

Note: $\mathrm{O}_{2}$ saturations measured with Kipp Haemoreflector. Pressures measured with Statham 23D transducer, relative to sternal angle.

TABLE II

Variations in Aortic and Pulmonary Arterial Pressures, Blood Gas Tensions, and $\mathrm{pH}$ under a Variety of Conditions in Case 1

\begin{tabular}{|c|c|c|c|c|c|c|c|c|c|}
\hline \multirow{2}{*}{$\begin{array}{l}\text { Time } \\
\text { (min.) }\end{array}$} & \multirow{2}{*}{\multicolumn{3}{|c|}{ State of Patient }} & \multicolumn{5}{|c|}{ Aortic } & \multirow{2}{*}{$\begin{array}{l}\text { Pulm. Artery } \\
\begin{array}{c}\text { Mean Pressure } \\
\text { (mm. Hg) }\end{array}\end{array}$} \\
\hline & & & & $\begin{array}{c}\mathrm{O}_{2} \text { Sat. } \\
\% \\
\%\end{array}$ & $\begin{array}{c}\mathrm{Po}_{2} \\
(\mathrm{~mm} \cdot \mathrm{Hg})\end{array}$ & $\begin{array}{c}\mathrm{PCO}_{2} \\
(\mathrm{~mm} . \mathrm{Hg})\end{array}$ & $p \mathrm{H}$ & $\begin{array}{c}\text { Mean } \\
\text { Pressure } \\
(\mathrm{mm} . \mathbf{H g})\end{array}$ & \\
\hline $\begin{array}{r}0 \\
40 \\
75 \\
100 \\
105\end{array}$ & $\begin{array}{l}\text { Asleep, breathing air } \\
\text { Crying, breathing air } \quad \ldots \\
\text { Crying, breathing } 100 \% \mathrm{O}_{2} \\
\text { Intubated, asleep breathing air } \\
\text { Intubated, awake breathing air }\end{array}$ & $\begin{array}{l}\cdots \\
\cdots \\
\cdots \\
\cdots\end{array}$ & $\begin{array}{l}\cdots \\
\cdots \\
\cdots \\
\cdots\end{array}$ & $\begin{array}{r}70 \cdot 5 \\
94 \\
100 \\
86 \\
89\end{array}$ & $\begin{array}{r}42 \\
76 \\
570 \\
64 \\
66\end{array}$ & $\begin{array}{l}76 \\
52 \\
48 \\
66 \\
48\end{array}$ & $\begin{array}{l}7 \cdot 28 \\
7 \cdot 39 \\
7 \cdot 37 \\
7 \cdot 24 \\
7 \cdot 32\end{array}$ & $\begin{array}{l}88 \\
88 \\
84 \\
66\end{array}$ & $\begin{array}{l}44 \\
26 \\
28 \\
24\end{array}$ \\
\hline \multicolumn{10}{|c|}{ Repeat cardiac catheterization after tonsillectomy } \\
\hline 0 & Awake, breathing air & $\cdots$ & $\ldots$ & 94 & 100 & 25 & $7 \cdot 39$ & 60 & 12 \\
\hline
\end{tabular}

Note: Blood gas tensions and $p \mathrm{H}$ measured by Astrup.

TABLE III

Variations in Aortic and Pulmonary Arterial Pressure, Blood Gas Tensions, and $\mathrm{pH}$ under Variety of Conditions in Case 2

\begin{tabular}{|c|c|c|c|c|c|c|c|c|c|c|c|c|}
\hline \multirow{2}{*}{$\begin{array}{l}\text { Time } \\
(\min .)\end{array}$} & \multirow{2}{*}{\multicolumn{2}{|c|}{ State of Patient }} & \multicolumn{4}{|c|}{ Aortic } & \multicolumn{4}{|c|}{ Pulm. Artery } & \multicolumn{2}{|c|}{$\begin{array}{l}\text { Mean Pressures } \\
\quad(\mathrm{mm} . \mathbf{H g})\end{array}$} \\
\hline & & & $\begin{array}{c}\mathrm{O}_{2} \text { Sat. } \\
(\%)\end{array}$ & $\frac{\mathrm{Po}_{2}}{(\mathrm{~mm} \cdot \mathrm{Hg})}$ & $\underset{(\mathrm{mm} . \mathrm{Hg})}{\mathrm{PCO}_{2}}$ & $p \mathrm{H}$ & $\begin{array}{c}\mathrm{O}_{2} \text { Sat. } \\
(\%)\end{array}$ & $\underset{(\mathrm{mm} . \mathrm{Hg})}{\mathrm{Po}_{2}}$ & $\underset{(\mathrm{mm} . \mathrm{Hg})}{\mathrm{PCO}_{2}}$ & $p \mathrm{H}$ & Aorta & $\begin{array}{l}\text { Pulm. } \\
\text { Art. }\end{array}$ \\
\hline $\begin{array}{r}0 \\
73 \\
99 \\
121\end{array}$ & $\begin{array}{l}\text { Crying, breathing air } \\
\text { Asleep, breathing air } \\
\text { Asleep, breathing } \mathrm{O}_{2}- \\
\text { enriched air. } \\
\text { Asleep, breathing air }\end{array}$ & $\begin{array}{l}\cdots \\
\cdots\end{array}$ & $\begin{array}{l}94 \\
86 \\
98 \cdot 5 \\
93 \cdot 5\end{array}$ & $\begin{array}{r}75 \\
62 \\
\\
141 \\
79\end{array}$ & $\begin{array}{l}34 \\
44 \cdot 5 \\
49 \\
40\end{array}$ & $\begin{array}{l}7 \cdot 37 \\
7 \cdot 30 \\
7 \cdot 25 \\
7 \cdot 32\end{array}$ & $\begin{array}{l}64 \cdot 5 \\
62 \\
71 \cdot 5 \\
64 \cdot 5\end{array}$ & $\begin{array}{l}38 \\
40 \\
47 \\
40\end{array}$ & $\begin{array}{l}38 \cdot 5 \\
45 \\
50 \cdot 4 \\
47\end{array}$ & $\begin{array}{l}7 \cdot 31 \\
7 \cdot 29 \\
7 \cdot 24 \\
7 \cdot 28\end{array}$ & $\begin{array}{r}108 \\
92 \\
104 \\
104\end{array}$ & $\begin{array}{l}24 \\
16 \\
\\
20 \\
18\end{array}$ \\
\hline
\end{tabular}

congestion of the lung fields. ECG (Fig. 6) showed right axis deviation, peaked $P$ waves in lead II measuring $4 \mathrm{~mm}$., rsR complex in $\mathrm{V} 1$, with $\mathrm{R}=19 \mathrm{~mm}$. The cause of this right atrial and right ventricular hypertrophy was obscure but there was no evidence of heart failure. We recommended that tonsillectomy and adenoidectomy should be performed because the upper respiratory obstruction was so severe; this was done on May 8. The tonsils and adenoids were very large indeed. No comment was made about the epiglottis. The child subsequently made excellent progress, and when seen on July 4 was breathing well without obstruction. There was no cyanosis, and the heart had decreased in size, now being within normal limits on $x$-ray (Fig. 7). The $\mathbf{P}$ waves in lead II now measured $2 \mathrm{~mm}$. and were no longer peaked; the $R$ wave in V1 measured $9 \mathrm{~mm}$. He was seen again on August 27 when his condition was excellent. Examination of his heart showed no abnormality and his ECG had returned to normal, the $R$ wave in lead V1 now measuring $4 \mathrm{~mm}$., and the $P$ waves in lead II being normal (Fig. 8).

In retrospect we feel that had not tonsillectomy been 


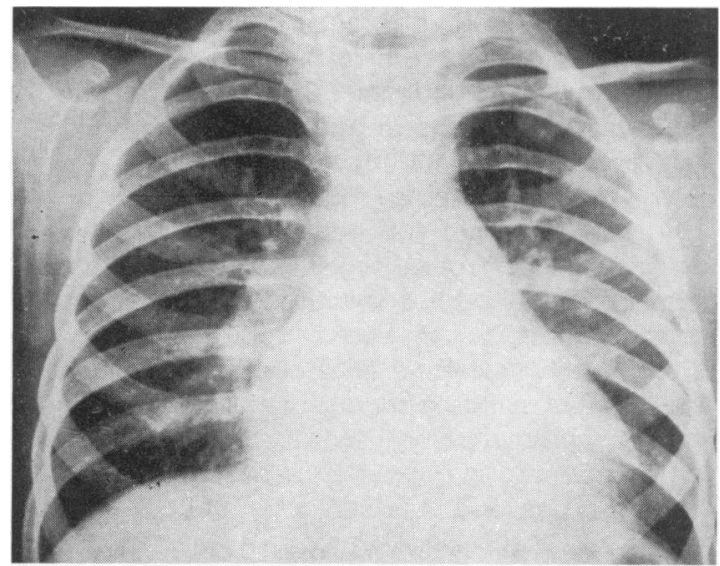

FIG. 5.-Chest x-ray before tonsillectomy in Case 3 shows increase in transverse diameter, prominent pulmonary artery, and fluffy hilar opacities.

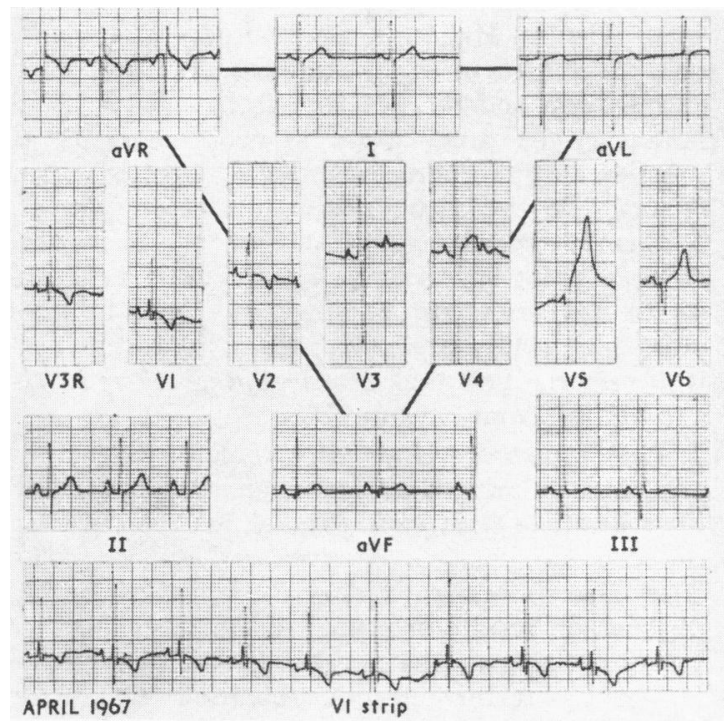

FIG. 6.-ECG in Case 3 before tonsillectomy shows right atrial hypertrophy (peaked $P$ waves in lead II), and right ventricular enlargement (tall $R$ wave in V3R and V1).

recommended for this boy, despite the fact that he was thought to have a cardiac lesion, he would probably have progressed in the same way as Case 1 , where tonsillectomy was deferred until the cardiac lesion had been diagnosed.

\section{Discussion}

Our initial experience in recognizing this condition was very much the same as that of others (Luke et al., 1966; Levy et al., 1967; Ainger,

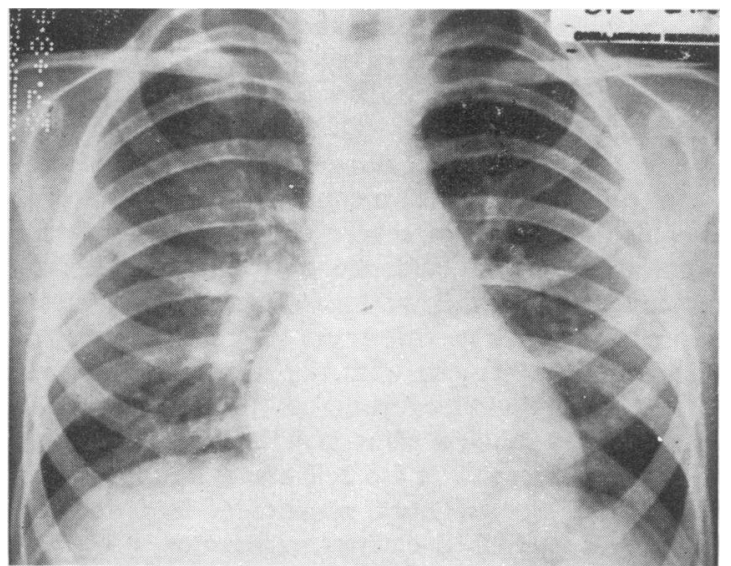

FIG. 7.-Chest $\mathrm{x}$-ray in Case 3, 2 months after tonsillectomy, shows reduction in heart size and pulmonary vascularity.

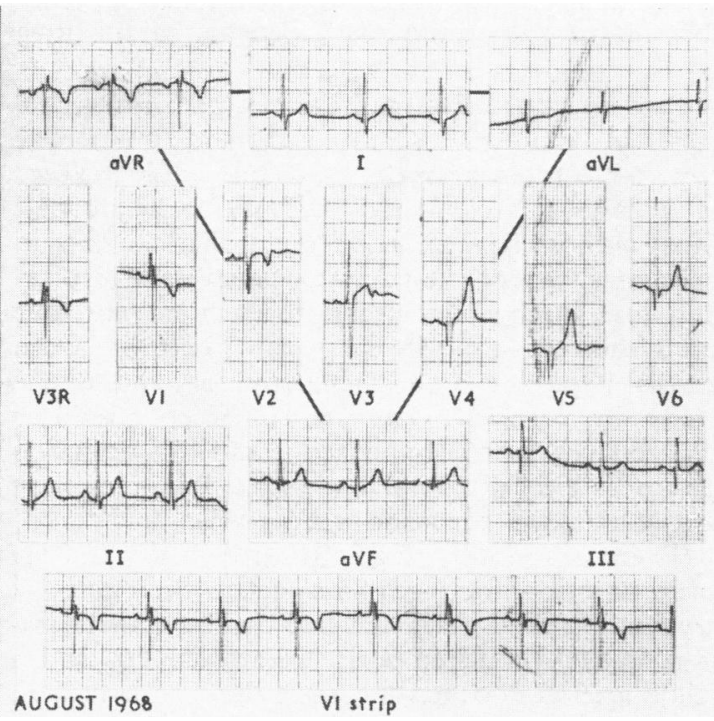

FIG. 8.-ECG in Case 3, 15 months after tonsillectomy. Record is now within normal limits.

1968). Preliminary diagnoses of cardiomyopathy or primary pulmonary hypertension were made, and only rejected when we observed the response to administration of $\mathrm{O}_{2}$, by which time the patient's condition had become critical. Yet, in retrospect, the clinical features of the disease are so striking that a firm diagnosis may be made with no more technical assistance than an ECG and an arterial blood sample. 
All 19 cases described in the literature, including our own, had marked stridor while in the supine position; in every case this was relieved by removal of tonsils and adenoids. Of these 19, 12 (the most severely affected) also showed somnolence, sometimes to the point of semiconsciousness. Cyanosis was also a feature in severe cases. In every case there was clinical evidence of pulmonary hypertension. In 14 this had resulted in right heart failure which was often considerable, and was resistant to treatment with digitalis and diuretics.

The ECG in all except one (Case 2, Menashe et al., 1965) showed right atrial hypertrophy, and in all cases except 2 (Case 2, Luke et al., 1966; and Case 2 this series) right ventricular hypertrophy. 5 of the 8 published electrocardiograms, including those shown here, exhibited striking deep $\mathrm{T}$ wave inversion over the right chest leads.

All of the 13 chest $x$-rays described (including our 3 cases) showed cardiomegaly, usually with prominence of the pulmonary artery, and 9 of 13 were thought to show pulmonary oedema in the lung fields.

Cardiac catheterization has been performed in 8 cases in addition to our own, and pulmonary hypertension has been the invariable finding except in 2 cases (Cases 3 and 4, Luke et al., 1966). Most authors have mentioned the marked dips in pulmonary artery pressure associated with inspiration due to the inspiratory obstruction, and our cases showed this. In every case there has been arterial hypoxaemia and $\mathrm{CO}_{2}$ retention, and as one study in particular has shown, sleep produces progressively greater hypoxaemia and $\mathrm{CO}_{2}$ retention together with progressive increase in pulmonary artery pressure (Menashe et al., 1965).

There is an interesting contrast between 2 of the cases described here with respect to the effects of crying. In the 2 cases that had cardiac catheterization, crying produced a rise in arterial $\mathrm{PO}_{2}$ and a fall in arterial $\mathrm{PCO}_{2}$ but in Case 1 this was associated with a fall in pulmonary artery pressure, whereas in Case 2 the pulmonary artery pressure was raised during crying. Crying in a normal child will raise the pulmonary artery pressure by increasing the cardiac output. It seems that in Case 1 this effect was more than counteracted by the pulmonary vasodilatation resultant upon the improvement in ventilation. In Case 2, which approaches more nearly the normal situation, presumably the reduction of pulmonary vascular resistance occasioned by the improvement in ventilation was small compared with the increase in cardiac output, so that the over-all effect upon the pulmonary artery pressure was to raise it.
Little information is available as to the acute effects of administration of $\mathrm{O}_{2}$ and improving the airway on these patients. In 1 child studied by Noonan (1965) a rise in pulmonary artery pressure was produced by administration of $100 \% \mathrm{O}_{2}$, the $\mathrm{PCO}_{2}$ meanwhile rising from 62 to more than $100 \mathrm{~mm}$. Hg. On the other hand Menashe and associates (1965) found that in their second case $\mathrm{O}_{2}$ administration caused a fall in pulmonary artery pressure, despite an increase in $\mathrm{CO}_{2}$ retention. In the case described by Levy et al. (1967), the insertion of a nasopharyngeal tube to relieve the airway obstruction caused a fall in pulmonary artery pressure at the same time as a rise in arterial $\mathrm{O}_{2}$ saturation and a fall in arterial $\mathrm{PCO}_{2}$. Subsequent $\mathrm{O}_{2}$ administration caused a small rise in $\mathrm{PCO}_{2}$ and a fall in the pulmonary artery pressure. In the first study described here, it was not possible to test the effect of $\mathrm{O}_{2}$ administration during sleep, but endotracheal intubation resulted in a marked fall in mean pulmonary artery pressure from 44 to $24 \mathrm{~mm}$. $\mathrm{Hg}$, while the arterial $\mathrm{O}_{2}$ saturation rose from 70.5 to $89 \%$, the $\mathrm{PCO}_{2}$ fell from 76 to $48 \mathrm{~mm} . \mathrm{Hg}$, and the $p \mathrm{H}$ rose from $7 \cdot 28$ to $7 \cdot 32$. However, the drugs given in order to assist intubation may themselves have affected these results. In the second case, intubation was not performed, but the administration of $\mathrm{O}_{2}$-enriched air to a point sufficient to raise arterial $\mathrm{Po}_{2}$ from 62 to $141 \mathrm{~mm}$. $\mathrm{Hg}$ resulted in a rise in mean pulmonary artery pressure from 16 to $20 \mathrm{~mm}$. $\mathrm{Hg}$, while arterial $\mathrm{PCO}_{2}$ rose from 44.5 to $49 \mathrm{~mm}$. $\mathrm{Hg}$, and $p \mathrm{H}$ fell from $7 \cdot 30$ to $7 \cdot 25$.

The studies described here confirm that in this syndrome pulmonary hypertension is associated with a low arterial $\mathrm{O}_{2}$ saturation and a high arterial $\mathrm{PCO}_{2}$, the classical changes of alveolar hypoventilation. They also show that relief of the upper respiratory obstruction results in return of all these abnormal values towards normal, and that administration of $\mathrm{O}_{2}$ results in further $\mathrm{CO}_{2}$ retention which may depress consciousness to dangerous levels, and may be associated with either a rise or a fall in pulmonary artery pressure. That artificiallyimposed upper respiratory obstruction causes reduced ventilation and $\mathrm{CO}_{2}$ retention has been demonstrated experimentally (Cherniack and Snidal, 1956).

What factors in the human are responsible for the control of pulmonary vascular resistance? There is little doubt that a major factor is arterial $\mathrm{Po}_{2}$, a fall in which causes pulmonary vasoconstriction (Euler and Liljestrand, 1946; Fishman, 1961; Enson et al., 1964). The role of arterial $\mathrm{PcO}_{2}$ and $p \mathrm{H}$ are more controversial, but there seems to be 
a growing amount of evidence for the important role of $p \mathrm{H}$ in the control of pulmonary vessel tone, since Liljestrand first pointed out that hypoxia, by promoting lactic acid release, increases hydrogen ion concentration which itself may cause pulmonary vasoconstriction (Liljestrand, 1958). The lower the arterial $\mathrm{O}_{2}$ saturation the greater is the effect of a change in $p \mathrm{H}$, and the higher the arterial $p \mathrm{H}$, the less sensitive is the pulmonary artery pressure to hypoxia (Enson et al., 1964; Harvey et al., 1967). These findings have been confirmed in the newborn calf (Rudolph and Yuan, 1966). Of particular interest in the context of this paper is a report of a study on a patient with the Pickwickian syndrome, the mechanism of which is presumably similar to that of cases of cor pulmonale due to upper respiratory obstruction. With voluntary hyperventilation a fall in pulmonary artery pressure was produced as well as a rise in arterial $\mathrm{O}_{2}$ saturation and arterial $p \mathrm{H}$. The administration of $100 \% \mathrm{O}_{2}$ caused no change in mean pulmonary artery pressure despite a significant increase in arterial $\mathrm{O}_{2}$ tension; and with administration of THAM, there was a decrease in both hydrogen ion concentration and pulmonary artery pressure, though the $\mathrm{O}_{2}$ tension remained essentially unchanged (Vogel and Blount, 1965).

In none of the cases so far described of cor pulmonale due to upper respiratory obstruction have the changes in cardiac output been measured; some of the rise in pulmonary artery pressure induced by a fall in arterial $p \mathrm{H}$ may be due to the resultant increase in cardiac output rather than to an increase in pulmonary vascular resistance.

In the cases reported here, as well as in others in the literature, there is a striking disparity between severity of right heart failure and severity of pulmonary hypertension. Right ventricular pressures of $200 \mathrm{~mm}$. Hg systolic may be tolerated in pulmonary stenosis for some years without heart failure supervening, yet in this syndrome it appears that an increase in right ventricular systolic pressure to $50 \mathrm{~mm}$. Hg for a few weeks may result in right ventricular failure. This may be the result of the acuteness of the right ventricular pressure load, or of depression of myocardial performance by a combination of hypoxaemia and acidaemia as Ainger (1968) has suggested, but it should be remembered that the incidental right ventricular pressure measured during right heart catheterization may be low by comparison with the pressure levels reached in the child after a night's sleep, with ever-increasing anoxia and $\mathrm{CO}_{2}$ retention.

The clinical implications of the existence of this syndrome are far reaching. Thousands of tonsil- lectomies are performed in this country each year and yet this complication of tonsillar and adenoidal hypertrophy has not been recognized. Many children with tonsils far larger than those of the children described here have no respiratory obstruction, and in fact are refused operation because there is insufficient indication for it. The first child described here had three sibs, all of whom had required tonsillectomy for various reasons, but he was the only one who developed this syndrome. This suggests that, in order to develop cor pulmonale in the presence of hypertrophied and infected tonsils and adenoids, some other factor must also be involved. The likeliest factor for this is an abnormal reactivity of the pulmonary vasculature to hypoxia such as that shown in approximately $20 \%$ of normal persons at altitude, and in some children with small ventricular septal defects (Grover et al., 1963). This mechanism has also been used to explain why not all grossly fat people develop the Pickwickian syndrome.

A possible explanation for the recognition of this syndrome in the past few years is that, with the trend towards conservatism in the management of infected tonsils and adenoids, this syndrome has been allowed to develop in children who 15 years ago would have had a tonsillectomy.

Nevertheless, it remains quite likely that some children suffering from this syndrome have been operated on and cured without the situation being appreciated. This happened in Case 3, the first patient we saw with early symptoms of this syndrome. Clearly, the administration of opiate premedication to such a child is fraught with the danger of exacerbating hypoventilation and thus producing excessive $\mathrm{CO}_{2}$ retention and even higher pulmonary artery pressures. Furthermore, the induction of anaesthesia is extremely likely to be complicated by complete respiratory obstruction unless special care is taken.

Ainger (1968) has reported 2 fatalities from this syndrome, so prompt recognition and treatment are important. Cardiac failure should if possible be abolished by medical treatment before operation, though if the failure proves intractable, operation may have to be carried out as an emergency.

Training the child to sleep in the prone position may be as valuable as any drug therapy, and the administration of $\mathrm{O}_{2}$, if it is given at all, should be subject to the same precautions as in an adult patient with cor pulmonale due to obstructive airway disease (i.e. $100 \% \mathrm{O}_{2}$ should never be given and $\mathrm{O}_{2}$-enriched air should only be given when constant watch is kept for the signs and symptoms of increasing $\mathrm{CO}_{2}$ retention). 


\section{Summary}

Three cases are reported of the syndrome of cor pulmonale in children due to chronic nasopharyngeal obstruction by hypertrophied tonsils and adenoids. The syndrome is characterized by: (1) Stridor in the supine position due to nasopharyngeal obstruction by hypertrophied tonsils and adenoids. (2) Somnolence. (3) Pulmonary hypertension. (4) Right heart failure. (5) Arterial hypoxia and hypercarbia. (6) Electrocardiographic changes suggestive of right atrial and right ventricular hypertrophy and right ventricular strain. (7) Radiographic appearances of cardiomegaly, dilatation of the pulmonary artery, and often pulmonary oedema.

The probable pathogenesis of the syndrome is that pulmonary hypoventilation leads to arterial hypoxaemia and acidaemia, which in turn lead to pulmonary vasoconstriction and hypertension. Cardiac failure should first be treated medically, and the tonsils and adenoids should subsequently be removed. Sleeping in the prone position often relieves the upper respiratory obstruction. $\mathrm{O}_{2}$ should be given with care since it may exacerbate the symptoms.

We wish to express our thanks to Dr. A. P. Roberts who referred Case 1, to Dr. E. Allibone who referred Case 2, to Dr. C. S. Livingstone who referred Case 3, and to Sister N. Fitzgerald who nursed 2 of these patients. We would also like to thank Miss M. Lockwood for her willing secretarial assistance.

\section{REFERENCES}

Ainger, L. E. (1968). Large tonsils and adenoids in small children with cor pulmonale. Brit. Heart $\mathcal{F}$., 30, 356.
Cherniack, R. M., and Snidal, D. P. (1956). The effect of obstruction to breathing on the ventilatory response to $\mathrm{CO}_{2}$. $\mathcal{f}$. clin. Invest., 35, 1286.

Enson, Y., Giuntini, C., Lewis, M. L., Morris, T. Q., Ferrer, M. I., and Harvey, R. M. (1964). The influence of hydrogen ion concentration and hypoxia on the pulmonary circulation. ibid., 43, 1146.

Euler, U. S. von, and Liljestrand, G. (1946). Observations on the pulmonary arterial blood pressure in the cat. Acta physiol. scand., 12, 301.

Fishman, A. P. (1961). Respiratory gases in the regulation of the pulmonary circulation. Physiol. Rev., 41, 214.

Grover, R. F., Vogel, J. H. K., Averill, K. H., and Blount, S. G., Jr. (1963). Pulmonary hypertension: individual and species variability relative to vascular reactivity. Amer. Heart $\mathcal{F}$., 66, 1.

Harvey, R. J., Enson, Y., Betti, R., Lewis, M. L., Rochester, D. F., and Ferrer, M. I. (1967). Further observations on the effect of hydrogen ion on the pulmonary circulation. Circulation, 35, 1019.

Levy, A. M., Tabakin, B. S., Hanson, J. S., and Narkewicz, R. M. (1967). Hypertrophied adenoids causing pulmonary hypertension and severe congestive heart failure. New Engl. F. Med., 277, 506.

Liljestrand, G. (1958). Chemical control of the distribution of the pulmonary blood flow. Acta physiol. scand., 44, 216.

Luke, M. J., Mehrizi, A., Folger, G. M., Jr., and Rowe, R. D. (1966). Chronic nasopharyngeal obstruction as a cause of cardiomegaly, cor pulmonale, and pulmonary edema. Pediatrics, 37, 762.

Menashe, V. D., Farrehi, C., and Miller, M. (1965). Hypoventilation and cor pulmonale due to chronic upper airway obstruction. F. Pediat., 67, 198.

Noonan, J. A. (1965). Reversible cor pulmonale due to hypertrophied tonsils and adenoids: studies in two cases. Amer. Pediat. Soc. Inc., May 6-8 (Abstracts), p. 48.

Rudolph, A. M., and Yuan, S. (1966). Response of the pulmonary vasculature to hypoxia and hydrogen ion concentration changes. f. clin. Inzest., 45, 399.

Vogel, J. H. K., and Blount, S. G., Jr. (1965). The role of hydrogen ion concentration in the regulation of pulmonary artery pressure. Circulation, 32, 788.

Correspondence to Dr. Olive Scott, Department of Paediatric Cardiology, Leeds Regional Thoracic Surgery Centre, Killingbeck Hospital, York Road, Leeds. 